\title{
南疆四种盐生植物根际土壤真菌群落结构特征
}

\author{
李明源 ${ }^{1,2,3, *}$, 王继莲 ${ }^{1,2,3}$, 周 茜 ${ }^{1,2,3}$, 张 甜 ${ }^{1,2,3}$, 美合热阿依・木台力甫 ${ }^{1,2,3}$ \\ 1 喀什大学生命与地理科学学院, 喀什 844006 \\ 2 叶尔㒸绿洲生态与生物资源研究自治区高校重点实验室,喀什 844006 \\ 3 新疆帕米尔高原生物资源与生态自治区重点实验室,喀什 844006
}

摘要:盐生植物特殊的生境孕育了独特的根际微生物群落。为了解南疆干旱区不同盐生植物根际土壤真菌群落结构特征, 探讨 影响真菌群落结构的土壤环境因子,选取南疆伽师县同一盐碱地盐爪爪(Kalidium foliatum)、黑果枸杞 (Lycium ruthenicum)、花 花柴 (Karelinia caspia) 和旱生芦苇( Phragmites australis) 四种优势盐生植物, 采用 Illumina NovaSeq 高通量测序技术分析根际土 壤真菌群落结构和多样性, 并探究其与土壤理化因子的相关性。结果表明,四种盐生植物根际土壤理化特征不尽相同, 土壤 $\mathrm{pH}$ 均超过 8.0 , 电导率 $(\mathrm{EC})$ 由高到低为旱生芦苇>盐爪爪>花花柴>黑果枸杞, 黑果枸杞根际土壤的有机质 $(\mathrm{SOM}) 、$ 全氮 $(\mathrm{TN}) 、$ 全 磷 $(\mathrm{TP})$ 、全钾 $(\mathrm{TK})$ 、速效氮 $(\mathrm{AN})$ 和速效磷 $(\mathrm{AP})$ 含量均最高, 旱生芦苇根际土壤的 SOM、TN、TP、TK 和 AN 值均最低, 但土壤水 分含量 $(\mathrm{SWC})$ 和 EC 值最高。四种盐生植物共有的操作分类单元 (OTUs) 数量为 153 个, 各自特有的 OTUs 数量不尽相同。根 际土壤真菌群落丰富度 (ACE、Chao 1 指数) 依次为盐爪爪>旱生芦苇 $>$ 黑果枸杞 >花花柴, Shannons 指灵第和 Simpson 指数大小 依次为盐爪爪>黑果枸杞 $>$ 旱生芦苇>花花柴。从四种盐生植物根际共检测到真菌 8 门、21 纲、44 目、89 科、124 属, 子囊菌门 (Ascomycota) 在四种盐生植物根际土壤中占绝对优势地位。镰狍菌属 (Fusarium)、支顶狍属 (Acremonium)、曲需属 (Aspergillus) 和青需菌属 (Penicillium) 是四种盐生植物根际土壤共有优势属, 非优势属数量多但相对丰度因植物种类而异。典范对应分析 ( CCA ) 显示, 土壤速效钾、 $\mathrm{AP} 、 \mathrm{pH}$ 和 $\mathrm{EC}$ 是影响根际土壤真菌群落结构变化的主要驱动因子。研究表明南疆四种盐生植物根际 土壤真菌群落具有相似性,但优势菌属丰度差异明显,具有植物种类特异性。

关键词:盐生植物;根际; 真菌; 群落结构

\section{Analysis on the rhizosphere fungal community structure of four halophytes in Southern Xinjiang}

\author{
LI Mingyuan $^{1,2,3, *}$, WANG Jilian ${ }^{1,2,3}$, ZHOU Qian ${ }^{1,2,3}$, ZHANG Tian ${ }^{1,2,3}$, MIHRAY • Mutallip ${ }^{1,2,3}$ \\ 1 Department of Biologic and Geographic Sciences, Kashi University, Kashi 844006, China \\ 2 Key Laboratory of Ecology and Biological Resources in Yarkand Oasis of Education of Xinjiang Uygur Autonomous Region, Kashi 844006, China \\ 3 Key Laboratory of Biological Resources and Ecology of Pamirs Plateau in Xinjiang Uygur Autonomous Region, Kashi 844006, China
}

\begin{abstract}
Halophytes harbour unique rhizosphere microbial communities as a result of their unique habitat. The rhizosphere soil fungal diversity and community structures of four halophytes, including Kalidium foliatum, Lycium ruthenicum, Karelinia caspia and Phragmites australis, typically distributed in the arid land of Southern Xinjiang, were studied using the Illumina high-throughput sequencing technology. The study aims to reveal the alpha diversity, species composition, abundance and the differences of rhizosphere soil fungi among the four halophytes, explore their correlation with environmental factors to provide the basis for further investigation of the relationship between rhizosphere soil microbes and
\end{abstract}

基金项目: 新疆维吾尔自治区高等学校科研计划项目(XJEDU2018Y038)

收稿日期: 2020-09-03; 网络出版日期:2021-07-05

*通讯作者 Corresponding author.E-mail: mingyuan_lee@ yeah.net 
salt tolerance of halophytes. The results showed that the physicochemical characteristics of the rhizosphere soil of the four halophytes were different. The soil $\mathrm{pH}$ was all over 8.0, and the electronic conductivity (EC) value from high to low was Phragmites australis, Kalidium foliatum, Karelinia caspia, Lycium ruthenicum. The soil organic matter ( SOM ), total nitrogen ( TN), total phosphorus (TP), total potassium (TK), available nitrogen ( AN) and available phosphorus (AP) contents in the rhizosphere soil of Lycium ruthenicum were the highest, while the SOM, TN, TP, TK and AN values were the lowest in Phragmites australis, but the SWC and EC value were the highest. The numbers of operational taxonomic units (OTUs) unique to Kalidium foliatum, Lycium ruthenicum, Karelinia caspia, and Phragmites australis were 51, 19, 11, and 53 respectively, as well as their common OTUs number was 153. The fungi community richness ( abundance-based coverage estimator, ACE and Chao 1 index) from high to low was Kalidium foliatum, Phragmites australis, Lycium ruthenicum, and Karelinia caspia. The fungal community was different in composition and abundance in the rhizosphere of the four halophytes. A total of 8 phyla, 21 classes, 44 orders, 89 families, and 124 genera fungi were detected in their rhizosphere soil samples. The relative abundance and distribution of fungi varied at phylum level, and the dominant groups were Ascomycota, Basidiomycota, and Chytridiomycota. There were 11, 9, 8, and 6 genera with relative abundance greater than $1 \%$ in the rhizosphere soil of Kalidium foliatum, Lycium ruthenicum, Karelinia caspia, and Phragmites australis, respectively, with 4 common dominant genera including Fusarium, Acremoniuma, Aspergillus and Penicillium. The number of non-dominant fungi was large but the relative abundance varied with plant species. Then each plant had its particular or mutual fungal genera with different abundance, some of which were affected greatly by soil physicochemical properties. According to canonical correlation analysis (CCA), we found that the major influence factors that caused the change of soil fungal community structures of the four halophytes were oil available potassium, available phosphorus, $\mathrm{pH}$ and electrical conductivity. This study revealed that the rhizosphere soil fungi communities of the four halophytes were similar, but the abundance of dominant bacteria was significantly different, with plant species specificity. The rhizosphere fungi community was correlated with the soil environmental factors.

Key Words: halophytes; rhizosphere; fungi; community structure

盐生植物是一类能在盐浓度 $200 \mathrm{mmol} / \mathrm{L} \mathrm{NaCl}$ 或更高的环境中生长并完成生活史的植物, 其对盐分胁迫 的适应性具有复杂的生化和遗传机制 ${ }^{[1]}$ 。多数盐生植物是盐碱地中唯一能够正常生存的植物种类, 它们在 盐碱地植被建植、水土保持及生态平衡的维系等方面起着至关重要的作用 ${ }^{[2-4]}$ 。在过去的几十年,有关盐生 植物耐盐碱胁迫的生理机制和基因表达变化等方面取得了很大进展 ${ }^{[5-6]}$, 但单纯利用传统育种方法或基因工 程改造技术来培育抗盐碱植物, 提升作物抗盐碱能力的成效有限。研究发现, 采用生物接种方法, 即将盐生植 物根际的少数有益微生物如丛枝菌根真菌 (AMF) 接种于植物, 能有效缓解盐碱胁迫对非盐生植物生长的抑 制作用 ${ }^{[7-9]}$, 对非盐生植物在盐碱环境中的生长、养分吸收及改善土壤质量有积极影响 ${ }^{[8,10-11]}$ 。挖掘盐生植物 根际的有益微生物作为促进非盐生植物生产的有效生物接种剂, 被认为是可持续提高非盐生植物耐盐碱性的 有效策略 ${ }^{[12-13]}$ 。

根际微生物与植物关系最为密切, 它们以植物根系分泌物为营养进行生长繁殖, 通过分泌各种胞外酶分 解、矿化土壤中的有机物质等增加土壤有效养分含量, 提高植物对养分的吸收 ${ }^{[14-15]}$ 。而植物在生长过程中通 过根系主动向根际土壤分泌生物活性物质, 吸引大量有益微生物在根际聚居并促进其生长发育, 进而对根 际微生物种类和数量产生影响 ${ }^{[16-17]}$ 。研究显示, 盐碱化问题的加剧不仅会对土壤微生物活性和群落组成产 生直接影响, 还能通过影响植物根系和土壤动物活动等对其产生间接作用 ${ }^{[18-19]}$ 。在盐碱土壤种植盐生植物 后, 既能有效降低根际土壤盐度, 使土壤微生物数量增加, 同时还会促使根际微生物群落结构发生改变, 通过 介导土壤环境反过来影响盐生植物生长 ${ }^{[13,20-21]}$ 。诸多学者相继开展了荒漠区、高寒草地等生境土壤真菌群 落研究 ${ }^{[22-23]}$, 分析了其与环境因子的互作效应, 但有关盐生植物根际土壤真菌多样性和群落结构的研究鲜见 
报道。

不同盐生植物的耐盐碱能力不同, 导致盐生植被的空间格局受盐碱化程度影响呈现一定地域性差异。新 疆作为我国最大的盐土区, 土壤盐分高, 碱性重, 严重限制了植物的分布和生存。而南疆又是全疆盐碱化趋势 最严重的区域 ${ }^{[24]}$, 在这样的生境中却生长着丰富的盐生植物, 其中一些种群还在盐碱荒漠植被形成过程中起 着主要建群作用,被认为是适合土壤修复的类群。这些土著盐生植物根际微生物群落结构特征如何? 同一盐 碱环境中不同种类的盐生植物根际微生物群落有何共性特征和个性差异? 对这类环境中不同盐生植物根际 微生物群落结构进行研究, 有助于发现对盐生植物耐盐碱胁迫有贡献的有益微生物类群, 对其开发利用在增 强非盐生植物抗逆性方面有巨大潜力。本研究以新疆南疆伽师县同一盐碱地中的四种盐生植物为材料, 采用 Illumina NovaSeq 测序平台对其根际土壤真菌群落结构和多样性进行分析, 并研究真菌群落结构与土壤环境 因子间的相关性, 旨在探究对盐生植物耐受盐碱胁迫有显著影响的关键微生物群落, 为盐碱地合理开发利用 提供理论依据。

\section{1 材料与方法}

\section{1 研究区概况及根际土壤样品采集}

伽师县堪称新疆南疆水苦低产的盐碱窝, 位于天山南麓, 塔里木盆地西缘, 是塔克拉玛干沙漠西缘的一块 绿洲。该区域地理坐标 $76^{\circ} 20^{\prime}-78^{\circ} 00^{\prime} \mathrm{E}, 39^{\circ} 16^{\prime}-40^{\circ} 00^{\prime} \mathrm{N}$, 属温带干旱荒漠气候, 多年平均降水量 $56 \mathrm{~mm}$, 年 蒸发量是年降水量的 40 倍。 20 世纪 80 年代全国第二次土壤普查结果表明,伽师县非盐碱化农耕土地面积 仅占全县耕地面积的 $1.9 \%$, 轻度盐碱化土地占 $14.2 \%$, 中度盐碱化土地占 $21.0 \%$, 重度盐碱化土地达 $63.0 \%$ 。土壤盐碱化已成为限制该地区植物生存和演替的主要因子, 导致土壤结构改变和肥力下降, 加速 了土地退化进程。研究区内植被主要包括柽柳 (Tamarix chinensis)、盐穗木 (Halostachys caspica)、黑果枸杞 (Lycium ruthenicum)、花花柴(Karelinia caspia)、盐爪爪(Kalidium foliatum)、旱生芦苇( Phragmites australis)、骆 驼刺 (Alhagi sparsifolia) 和碱蓬 (Suaeda glauca), 交错分布。

2019 年 8 月, 依据典型性和代表性原则, 采集伽师县夏普吐勒乡境内非开垦干旱盐碱荒地 $\left(76^{\circ} 55^{\prime} \mathrm{E}\right.$, $39^{\circ} 49^{\prime} \mathrm{N}$ ) 盐爪爪、黑果枸杞、花花柴和旱生芦苇四种优势土著盐生植物根际土壤。采样方法为多点混合采样 法, 即在样区内采取 “ $S$ ” 型路线随机布点 12 处, 样点之间距离不少于 $20 \mathrm{~m}$ 。每种植物在每个采样点均选取生 长旺盛且冠幅大小一致的健康个体采集 $1-2$ 株。先去除 $0-5 \mathrm{~cm}$ 的表土, 深挖取出整株根系 (约 20-40 $\mathrm{cm}$ ), 轻轻抖去根系上附着较松散的土壤, 保留与根系紧密结合的土壤 (约 $1-3 \mathrm{~mm}$ ), 小心剪下根系装入 50 $\mathrm{mL}$ 无菌离心管中, 每 3 个相邻样点采集的相同植物根系再混合为一个样品, 最终得到每种植物 4 个重复样 品,4 种植物共 16 个样品,于低温下带回实验室,迅速进行根际土壤基因组提取。

\section{2 研究方法}

\subsection{1 土壤理化性质分析}

相同植物根际土壤样品以四分法混匀,过篮去除杂草、砾石等杂质,参照《土壤农化分析》方法测定土壤 理化指标 ${ }^{[26]}$ 。采用电位法测定土壤 $\mathrm{pH}$; 水土比 $5: 1$ 混合测定土壤电导率 $(\mathrm{EC}) ; 105^{\circ} \mathrm{C}$ 烘干称重法测定土壤含 水量 $(\mathrm{SWC})$; 重铬酸钾容重法测定土壤有机质 $(\mathrm{SOM})$; 重铬酸钾-硫酸消煮法测定土壤全氮 $(\mathrm{TN})$; 硫酸-高氯 酸消煮、钼锑抗比色法测定土壤全磷 ( TP ) ; $\mathrm{NaOH}$ 熔融-火焰光度法测定土壤全钾 ( TK) ; 碱解扩散法测定土壤 速效氮 $(\mathrm{AN}) ; \mathrm{NaHCO}_{3}$ 浸提-钿锑抗比色法测定土壤速效磷 $(\mathrm{AP}) ; \mathrm{NH}_{4} \mathrm{OAc}$ 浸提-火焰光度法测定土壤速效钾 $(\mathrm{AK})$ 。

\subsection{2 土壤基因组 DNA 提取}

采用土壤基因组 DNA 提取试剂盒( OMEGA E.Z.N.A. Soil DNA Kit, USA) 提取总 DNA。向装有植物根系 的 $50 \mathrm{~mL}$ 离心管中加人生理盐水 $(0.85 \% \mathrm{NaCl}) 30 \mathrm{~mL}$, 约 30 颗无菌玻璃珠 $(\varphi 3 \mathrm{~mm}$ ), 涡旋振荡 $10 \mathrm{~min}$ 后弃根 系, 所得根际土壤溶液经 $4^{\circ} \mathrm{C} 、 16000 \mathrm{~g}$ 离心 $10 \mathrm{~min}$ 弃上清, 参照土壤基因组 DNA 提取试剂盒说明书提取 
DNA。采用 $0.7 \%$ 琼脂糖凝胶电泳检测, 利用微量紫外分光光度计 (Nanodrop 2000) 检验基因组纯度和浓度后 于 $-20^{\circ} \mathrm{C}$ 保存。

\subsection{3 真菌 ITS 基因扩增与测序}

以土壤总 DNA 为模板, 采用引物 ITS1-1F-F ( $5^{\prime}$-CTTGGTCATTTAGAGGAAGTAA- $3^{\prime}$ ) 和 ITS1-1F-R ( $5^{\prime}$ GCTGCGTTCTTCATCGATGC- $3^{\prime}$ ) 扩增真菌 ITS1 基因片段,每个 DNA 模板做三个重复。PCR 反应条件参照 Miao 等 ${ }^{[27]}$ 方法: $95^{\circ} \mathrm{C}, 2 \mathrm{~min} ; 95^{\circ} \mathrm{C}, 30 \mathrm{~s} ; 55^{\circ} \mathrm{C}, 30 \mathrm{~s} ; 72^{\circ} \mathrm{C}, 45 \mathrm{~s} ; 30$ 个循环; $72^{\circ} \mathrm{C}$ 再延伸 $5 \mathrm{~min}$ 。PCR 产物经 $1 \%$ 琼脂糖凝胶电泳检测后送测序公司 (北京诺禾致源生物信息科技有限公司), 采用 Illumina NovaSeq 测序平台 进行双末端测序。

\subsection{4 数据分析}

依据 PCR 扩增引物和 Barcode 序列对 Illumina NovaSeq 下机数据进行初步拆分, 得到各样品的原始数据。 去除 Barcode 序列和低质量碱基后, 使用 FLASH(V1.2.7)软件拼接各样品的原始序列, 得到 Clean Tags, 再进 行嵌合体过滤, 得到最终有效数据 ${ }^{[28]}$ 。利用 Uparse 软件( Uparse V7.0.1) 对各样品有效数据在 $97 \%$ 相似性水 平上进行操作分类单元 (OTU) 截断聚类, 同时篮选 OTUs 中出现频数最高的序列作为代表序列。利用 Qiime 软件(V1.9.1) 中的 blast 方法与 Unit( V7.2) 数据库进行物种注释,并分别在各个分类水平统计各样本的群落 组成。使用 MUSCLE(3.8.31) 软件进行快速多序列比对建树, 获取全部 OTUs 代表序列的系统分类地位。各 样品最终数据经均一化处理后使用 Qiime 软件计算丰富度和多样性指数; 利用 R 软件绘制 Rank Abundance 曲线、稀释曲线以及 PCA 图等; 通过典范对应分析 (CCA) 研究土壤真菌群落和理化因子之间的相关性。利用 SPSS 21.0 软件对所有数据进行单因素方差分析 (One-Way ANOVA) 和 Duncan 新复极差法检验。数据为平均 值土标准差。

\section{2 结果与分析}

\section{1 土壤理化性质}

四种盐生植物根际土壤理化特征不尽相同 (表 1)。土壤 $\mathrm{pH}$ 均超过 8.0,但盐爪爪与旱生芦苇显著高于黑 果枸杞和花花柴。EC 由高到低为旱生芦苇>盐爪爪>花花柴>黑果枸杞,说明旱生芦苇与盐爪爪根际土壤中混合 盐含量明显高于花花柴和黑果枸杞, 能聚集盐离子或更偏好高盐碱环境。黑果枸杞根际土壤的 SOM、TN、TP、 $\mathrm{TK} 、 \mathrm{AN}$ 和 $\mathrm{AP}$ 值均最高, 旱生芦苇根际土壤的 SOM 、TN、TP、TK 和 AN 值均最低, 但 SWC 和 EC 值最高。

表 1 四种盐生植物根际土壤理化特征

Table 1 Physical and chemical characteristics of rhizosphere soil of four halophytes

\begin{tabular}{|c|c|c|c|c|}
\hline $\begin{array}{l}\text { 参数 } \\
\text { Parameter }\end{array}$ & $\begin{array}{c}\text { 盐爪爪 } \\
\text { Kalidium foliatum }\end{array}$ & $\begin{array}{c}\text { 黑果枸杞 } \\
\text { Lycium ruthenicum }\end{array}$ & $\begin{array}{c}\text { 花花柴 } \\
\text { Karelinia caspia }\end{array}$ & $\begin{array}{c}\text { 旱生芦苇 } \\
\text { Phragmites communis }\end{array}$ \\
\hline $\mathrm{pH}$ & $8.42 \pm 011 \mathrm{a}$ & $8.20 \pm 0.14 b$ & $8.21 \pm 0.15 b$ & $8.39 \pm 0.13 \mathrm{a}$ \\
\hline $\mathrm{EC} /(\mu \mathrm{s} / \mathrm{cm})$ & $5.12 \pm 0.79 \mathrm{~b}$ & $2.84 \pm 0.86 \mathrm{~d}$ & $3.15 \pm 0.33 c$ & $9.10 \pm 0.67 \mathrm{a}$ \\
\hline $\mathrm{SWC} / \%$ & $11.91 \pm 0.39 \mathrm{bc}$ & $11.09 \pm 0.13 \mathrm{c}$ & $12.14 \pm 0.07 \mathrm{~b}$ & $15.39 \pm 0.96 \mathrm{a}$ \\
\hline $\mathrm{SOM} /(\mathrm{g} / \mathrm{kg})$ & $12.82 \pm 0.17 \mathrm{c}$ & $20.55 \pm 0.12 \mathrm{a}$ & $15.95 \pm 0.98 b$ & $11.30 \pm 0.77 \mathrm{~d}$ \\
\hline $\mathrm{TN} /(\mathrm{g} / \mathrm{kg})$ & $0.68 \pm 0.93 \mathrm{a}$ & $0.78 \pm 0.41 \mathrm{a}$ & $0.72 \pm 0.08 \mathrm{a}$ & $0.63 \pm 0.54 \mathrm{a}$ \\
\hline $\mathrm{TP} /(\mathrm{g} / \mathrm{kg})$ & $0.53 \pm 0.67 b$ & $0.59 \pm 0.86 \mathrm{a}$ & $0.55 \pm 0.58 b$ & $0.48 \pm 0.78 \mathrm{c}$ \\
\hline $\mathrm{TK} /(\mathrm{g} / \mathrm{kg})$ & $4.04 \pm 0.23 \mathrm{a}$ & $4.14 \pm 0.02 \mathrm{a}$ & $3.89 \pm 0.76 \mathrm{a}$ & $3.36 \pm 0.35 \mathrm{~b}$ \\
\hline $\mathrm{AN} /(\mathrm{mg} / \mathrm{kg})$ & $84.23 \pm 0.76 b$ & $93.75 \pm 0.27 \mathrm{a}$ & $85.76 \pm 0.98 b$ & $78.09 \pm 0.18 \mathrm{c}$ \\
\hline $\mathrm{AP} /(\mathrm{mg} / \mathrm{kg})$ & $12.69 \pm 0.25 \mathrm{c}$ & $36.04 \pm 0.61 \mathrm{a}$ & $14.18 \pm 0.31 \mathrm{c}$ & $26.53 \pm 0.68 \mathrm{~b}$ \\
\hline $\mathrm{AK} /(\mathrm{mg} / \mathrm{kg})$ & $315.24 \pm 0.89 \mathrm{~d}$ & $334.96 \pm 0.61 \mathrm{c}$ & $376.80 \pm 0.17 \mathrm{a}$ & $353.52 \pm 0.78 b$ \\
\hline
\end{tabular}

EC: 电导率 Electronic conductivity; SWC: 土壤含水量 Soil water content; SOM : 土壤有机质质 Soil organic matter; TN: 全氮 Total nitrogen; TP : 全 磷 Total phosphorus; TK: 全钾 Total potassium; AN : 速效氮 Available nitrogen; AP: 速效磷 Available phosphorus; AK: 速效钾 Available potassium; 同 行不同小写字母表示差异显著 $(P<0.05)$

2.2 真菌群落丰度及多样性分析

测序结果表明,各样本测得有效数据长度在 238-241 bp 之间,平均长度 239 左右。测序数据质控后共 
得到 981983 条有效序列 (表 2), 以 $97 \%$ 的一致性将序列聚类成 564 个 OTUs。由各样本稀释曲线可见 (图 1), 随测序深度增加, 曲线趋向平坦, 说明样本测序数据量合理, 能够准确反映四种盐生植物根际土壤真 菌群落特征。四种盐生植物根际土壤真菌群落丰富度 (ACE、Chao 1 指数) 依次为盐爪爪>旱生芦苇>黑果枸 杞>花花柴, 黑果枸杞与花花柴根际真菌丰富度指数无显著差异 $(P>0.05)$ 。Shannon 指数和 Simpson 指数依 次为盐爪爪>黑果枸杞>旱生芦苇>花花柴, 旱生芦苇与黑果枸杞之间无显著差异 $(P>0.05)$ 。表明四种盐生植 物根际真菌群落多样性和丰富度各不相同。

表 2 四种盐生植物根际土壤真菌 ITS 测序数据统计及 alpha 多样性分析

Table 2 Statistics of ITS amplitor sequencing data of rhizosphere soil fungi and alpha diversity analysis for four halophytes

\begin{tabular}{cccccccc}
\hline $\begin{array}{c}\text { 样品名称 } \\
\text { Sample name }\end{array}$ & $\begin{array}{c}\text { 序列数 } \\
\text { Seq amount }\end{array}$ & $\begin{array}{c}\text { OTUs 数量 } \\
\text { OTUs amount }\end{array}$ & $\begin{array}{c}\text { Shannon 指数 } \\
\text { Shannon index }\end{array}$ & $\begin{array}{c}\text { Shannon 指数 } \\
\text { Shannon index }\end{array}$ & $\begin{array}{c}\text { ACE 指数 } \\
\text { ACE index }\end{array}$ & $\begin{array}{c}\text { Chao } 1 \text { 指数 } \\
\text { Chao } 1 \text { index }\end{array}$ & $\begin{array}{c}\text { 测序深度指数 } \\
\text { Good's Coverage }\end{array}$ \\
\hline 盐爪爪 & 206419 & 453 & $5.01 \pm 0.12 \mathrm{a}$ & $0.93 \pm 0.00 \mathrm{a}$ & $361.92 \pm 25.93 \mathrm{a}$ & $429.79 \pm 96.16 \mathrm{a}$ & 0.99 \\
黑果枸杞 & 259605 & 294 & $4.03 \pm 0.04 \mathrm{~b}$ & $0.87 \pm 0.01 \mathrm{ab}$ & $221.98 \pm 3.50 \mathrm{~b}$ & $216.05 \pm 2.77 \mathrm{~b}$ & 0.99 \\
花花柴 & 261326 & 241 & $3.34 \pm 0.14 \mathrm{c}$ & $0.78 \pm 0.03 \mathrm{c}$ & $190.05 \pm 6.75 \mathrm{~b}$ & $186.73 \pm 7.63 \mathrm{~b}$ & 0.99 \\
旱生芦苇 & 254633 & 404 & $4.02 \pm 0.16 \mathrm{~b}$ & $0.82 \pm 0.10 \mathrm{bc}$ & $313.12 \pm 4.02 \mathrm{a}$ & $303.11 \pm 5.42 \mathrm{ab}$ & 0.99 \\
\hline
\end{tabular}

根据聚类结果分析它们共有和特有的 OTUs ( 图 $2)$ 。盐爪爪和黑果枸杞共有的 OTUs 数量为 250 个,盐 爪爪和花花柴共有的 OTUs 数量为 216 个,盐爪爪和旱 生芦苇共有的 OTUs 数量为 332 个, 黑果枸杞和花花柴 共有的 OTUs 数量为 192 个,花花柴和旱生芦苇共有的 OTUs 数量为 171 个, 四种盐生植物之间共有 OTUs 数 量为 153 个。盐爪爪、黑果枸杞、花花柴和旱生芦苇特 有的 OTUs 数量分别为 $51 、 19 、 11$ 和 53 个, 占各自根际 土壤真菌 OTUs 总数的 $9.04 \% 、 3.37 \% 、 1.95 \%$ 和 $9.40 \%$ 。

2.3 四种盐生植物根际土壤真菌群落分布特征

2.3.1 门水平群落组成与结构

四种盐生植物根际土壤样品中共检测出真菌 8 门、 21 纲、44 目、89 科、124 属。如图 3 所示, 子囊菌门 (Ascomycota) 是四种盐生植物根际土壤真菌的绝对优

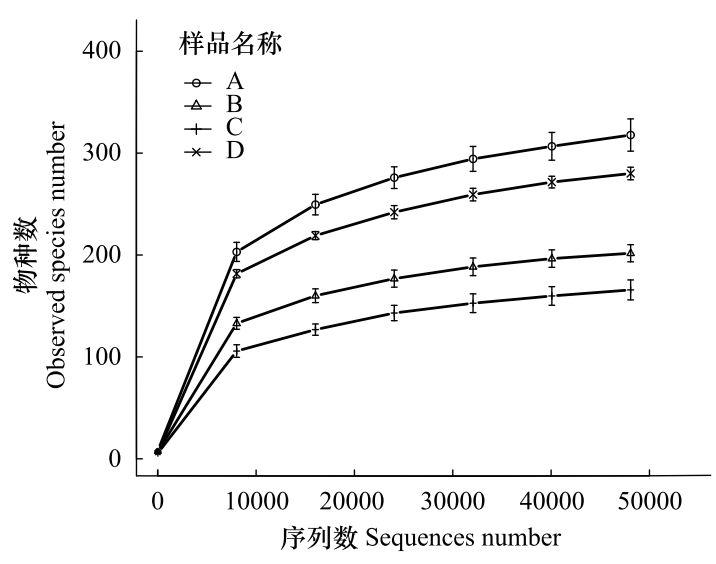

图 1 样本稀释曲线

Fig.1 Rarefaction curves for samples

A. 盐爪爪; B. 黑果枸杞; C. 花花柴; D. 旱生芦苇 势菌群, 其相对丰度在花花柴根际占比最高 (94.8\%), 在旱生芦苇根际占比最低 (74.6\%)。担子菌门 (Basidiomycota) 为亚优势菌门,在四种植物根际的相对丰度在 $0.3 \%$ - $1 \%$ 之间。排列第三的是壸菌门 (Chytridiomycota), 但该门仅分布在盐爪爪和旱生芦苇根际土壤中, 相 对丰度分别为 $0.93 \%$ 和 $0.74 \%$ 。被狍嚅门 (Mortierellomycota) 在黑果枸杞根际土壤的相对丰度达 $1.1 \%$, 但在 其它三种植物中几乎没有检测到。基于 Unweighted Unifrac 距离的 UPGMA 聚类树也可以发现(图 4), 四种盐 生植物根际土壤真菌群落在门水平上相对丰度不一,盐爪爪和旱生芦苇根际土壤真菌群落组成更相似。

\subsection{2 属水平群落组成与结构}

如图 5 所示, 四种盐生植物根际土壤真菌群落在属水平上相对丰度各不相同, 优势菌属和特有菌属也不 尽相同, 镰狍菌属 (Fusarium) 、支顶狍属 (Acremonium) 和曲霉属 (Aspergillus) 是它们共有优势菌属。从植物种 类看, 盐爪爪根际土壤中相对丰度大于 $1 \%$ 的属分别为镰孢菌属 $(22.31 \%)$ 、微囊菌属 (Microascus) (9.74\%)、 梨狍帚霉属 (Scopulariopsis) (7.37\%)、青霉菌属 (Penicillium) (5.16\%)、支顶狍属 $(4.41 \%)$ 、曲霉属 $(2.97 \%) 、$ 瓶霉菌属 (Phialophora) (2.81\%)、翅狍壳属 (Emericellopsis) (2.03\%)、格狍腔菌属 (Pleospora) $(2.03 \%) 、$ 单胞瓶 霉属 (Phialemonium) $(1.96 \%)$ 和链格孢属 (Alternaria) (1.93\%), 其中镰狍菌属占主导地位。黑果枸杞根际土 


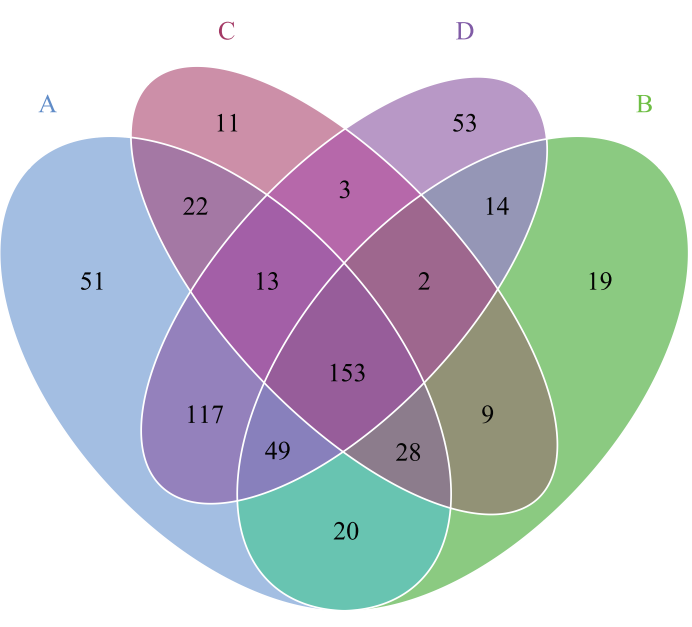

图 2 四种盐生植物之间共有和特有 OTUs 分析

Fig.2 Common and endemic OTUs analysis among the four halophytes

图中每个圈代表一种盐生植物, 重叠部分的数字代表样本之间共 有的 OTUs 数量, 非重叠部分的数字代表样本的特有 OTUs 数量

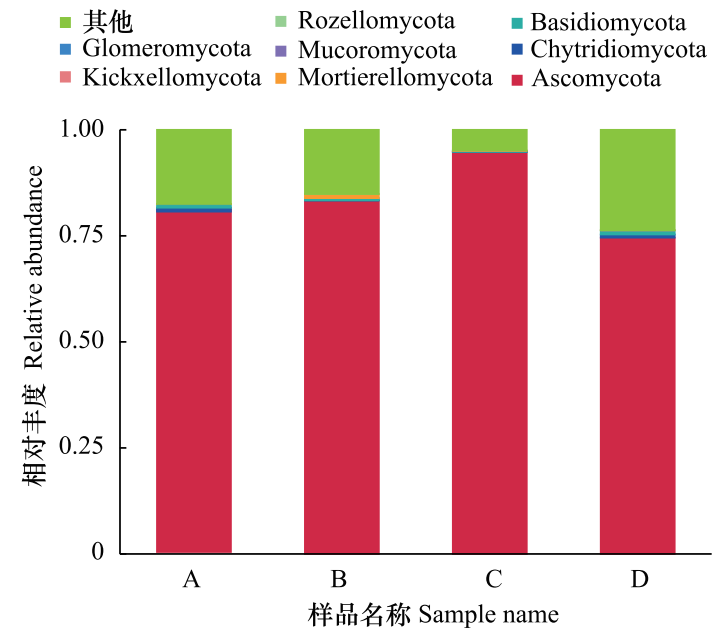

图 3 门水平上四种盐生植物根际土壤真菌群落分布特征

Fig.3 Histogram of relative abundance of fungal species at phylum level

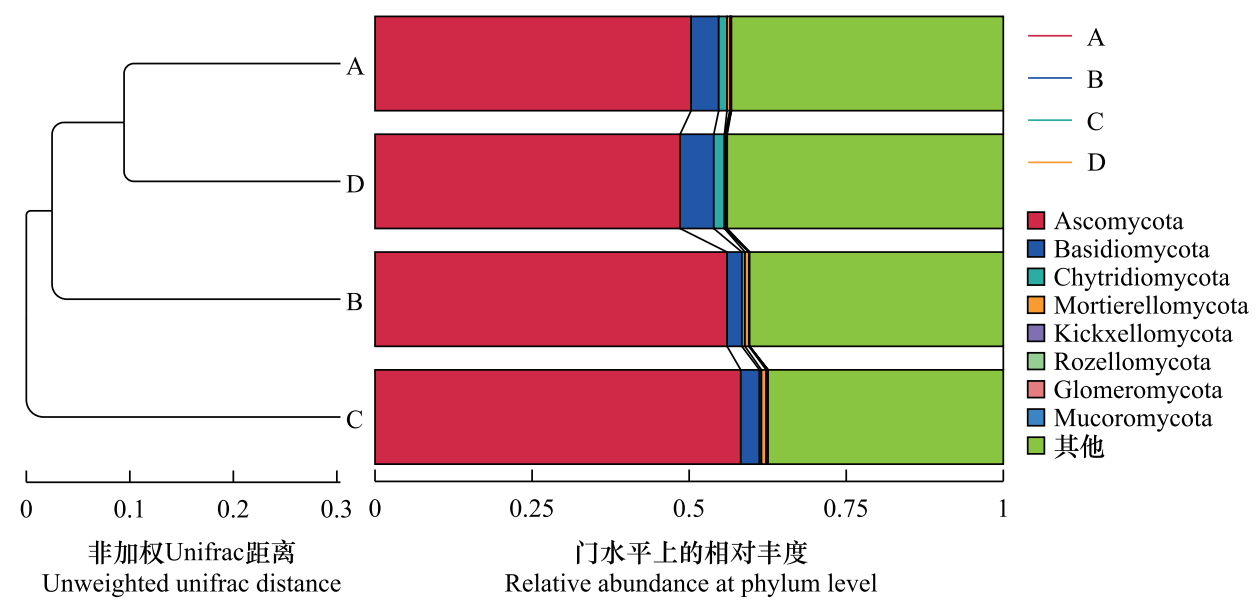

图 4 基于 Unweighted Unifrac 距离的 UPGMA 聚类树

Fig.4 UPGMA cluster tree based on Unweighted Unifrac distance

壤中相对丰度大于 $1 \%$ 的属分别为镰狍菌属 (30.83\%)、曲霉属 $(15.26 \%)$ 、链格狍属 $(10.25 \%) 、$ 、梨狍帚霉属 (9.85\%)、青霉菌属 $(4.21 \%)$ 、支顶狍属 $(3.25 \%)$ 、茎点霉属 $(P h o m a)(2.77 \%)$ 、翅狍壳属 $(2.52 \%)$ 和微霅菌属 ( $1.51 \%)$, 其中镰狍菌属、曲霉属和链格狍属占主导地位。花花柴根际土壤中相对丰度大于 $1 \%$ 的属分别为支顶

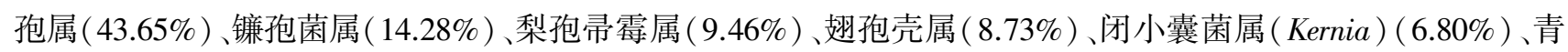
霉菌属 (3.23\%)、曲霉属 $(2.56 \%$ ) 和帚枝霉属 (Sarocladium) (1.01\%), 其中支顶孢属和镰孢菌属占主导地位。旱 生芦苇根际土壤中相对丰度大于 $1 \%$ 的属分别为镰狍菌属 (38.41\%)、支顶狍属 $(8.96 \%)$ 、曲霉属 $(7.98 \%) 、$ 、链格狍 属 $(6.16 \%$ )、青霉菌属 $(1.51 \%)$ 和地丝需属 (Geomyces) (1.04\%), 其中镰狍菌属占主导地位。

相比而言, 四种盐生植物根际优势真菌在群落组成上具有一定相似性, 但相对丰度存在明显差异。从属 水平物种系统发生关系和相对丰度聚类分析可以看出 (图 6), 镰狍菌属是四种盐生植物根际的共同优势菌 属, 但它在花花柴根际的相对丰度显著低于其它三种植物。支顶狍属在花花柴根际土壤中占绝对优势, 相对 丰度达 $43.65 \%$, 但在另外三种植物根际的相对丰度却均低于 $10 \%$ 。曲霉属在黑果枸杞根际的丰度最高 
(15.26\%), 是黑果枸杞根际土壤中的次优势菌属,但在 其它三种植物根际却不占主导地位。链格狍属在黑果 枸杞根际土壤中相对丰度排列第三, 是早生芦苇根际土 壤中的第四优势菌属, 但在盐爪爪和花花柴根际土壤真 菌群落中却不占优势 (相对丰度小于 $1 \%$ )。茎点霉属 在黑果枸杞根际土壤中的相对丰度达 $2.77 \%$, 而在其它 植物根际的丰度均低于 $0.2 \%$ 。梨狍帚霉属在旱生芦苇 根际的丰度仅 $0.2 \%$, 而在其它植物根际的分布丰度却 均超过 $7 \%$, 属于亚优势菌属。微囊菌属在盐爪爪根际 土壤中是仅次于镰孢菌属的亚优势菌属, 而在另外三种 植物根际土壤中的相对丰度却较低。闭小囊菌属在花 花柴根际的相对丰度达 $6.79 \%$, 而在其它植物根际分布 极少。格狍腔菌属在盐爪爪根际的相对丰度达 $2.03 \%$, 而在其它植物根际几乎没有发现。

2.4 根际土壤真菌群落结构与土壤理化因子间的相互 关系

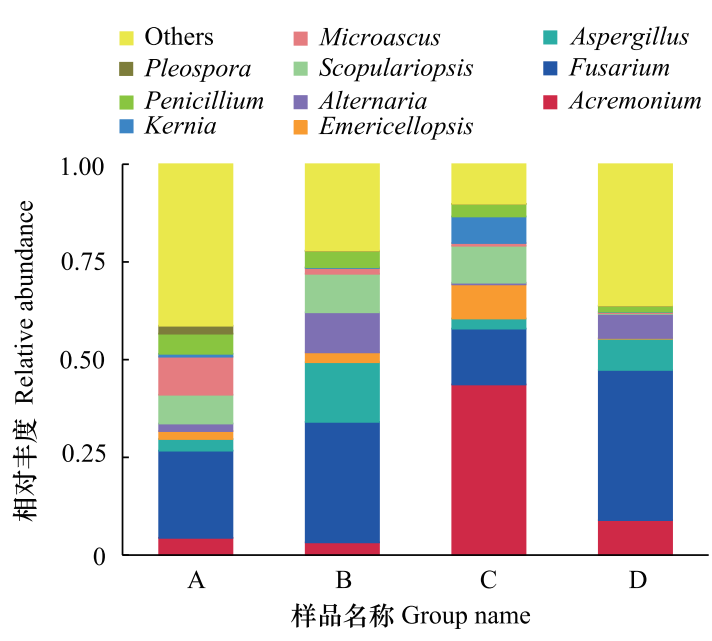

图 5 属水平上四种盐生植物根际土壤真菌群落分布特征

Fig.5 Distribution characteristics of rhizosphere fungal communities of four halophytes at genus level

通过 CCA 分析真菌群落与土壤理化因子间的相关性(图 7 ), 第一、二排序轴累计解释率分别为 $51.72 \%$

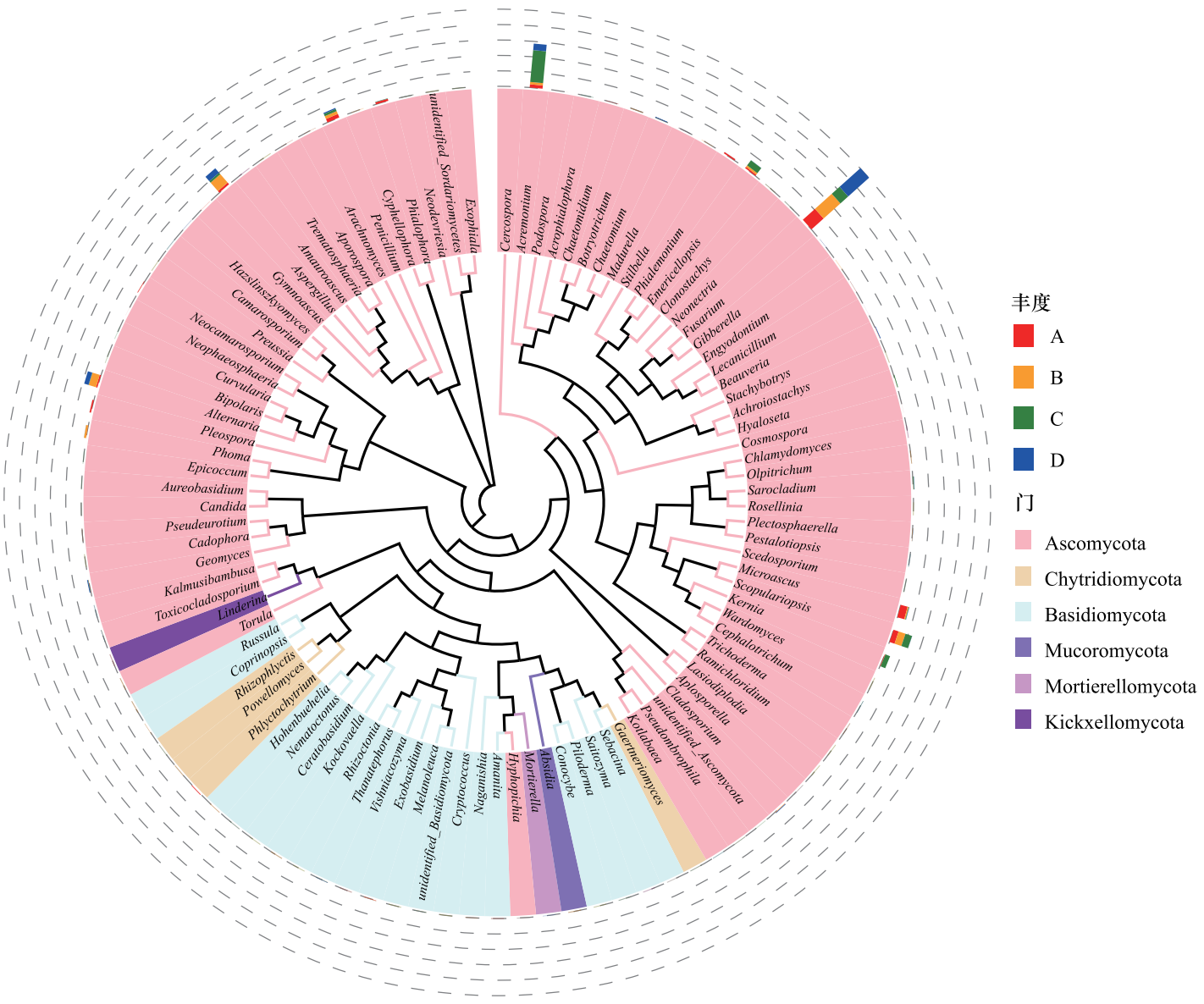

图 6 属水平上物种系统发生关系

Fig.6 Phylogenetic tree constructed with representative sequences of species at genus level 分支和扇形的颜色表示其对应的门,扇环外侧的堆积柱形图表示该菌属在不同样本中的丰度分布信息 
和 $29.6 \%$, 累计解释率达到 $81.32 \%$, 说明第一 二排序轴能较好地反映出真菌群落与土壤理化因子之间的相 互关系。真菌群落的差异性分布主要约束在第一轴和第二轴。对于第一轴,较重要的环境因子分别是 $\mathrm{AK}$ 、 $\mathrm{AP}$ 和 $\mathrm{EC}$, 因为这些因子与第一轴夹角很小 (分别为 $46.5^{\circ} 、 48.4^{\circ}$ 和 $12.0^{\circ}$ ), 即投影较长。约束在第二轴上的 重要的环境因子为 $\mathrm{AK} 、 \mathrm{AP}$ 和 $\mathrm{pH}$ 。镰孢菌属、曲霉属和链格孢属与 $\mathrm{AP} 、 \mathrm{EC}$ 和 $\mathrm{SWC}$ 箭头方向相同, 说明这 3 属真菌的分布丰度与 $\mathrm{AP} 、 \mathrm{EC}$ 和 SWC 之间呈正相关。青震菌属和梨狍帚震属与 $\mathrm{pH} 、 \mathrm{TK}$ 箭头方向相同, 说明 其群落丰度与土壤 $\mathrm{TK}$ 和 $\mathrm{pH}$ 呈正相关。支顶狍属、翅狍壳属和闭小囊菌属与 $\mathrm{AK}$ 呈正相关, 与 $\mathrm{pH} 、 \mathrm{AP}$ 和 $\mathrm{EC}$ 呈负相关。

综上, 对真菌群落结构具有重要影响因素的土壤指标有: AK $\left(r^{2}=0.893, P<0.01\right), \mathrm{AP}\left(r^{2}=0.725, P<\right.$ $0.01), \mathrm{pH}\left(r^{2}=0.505, P<0.01\right)$ 和 $\mathrm{EC}\left(r^{2}=0.334, P<0.05\right)$ (表 3$)$ 。土壤速效钾、速效磷、 $\mathrm{pH}$ 和电导率是影响四 种盐生植物根际土壤真菌群落分布的主要驱动因子。

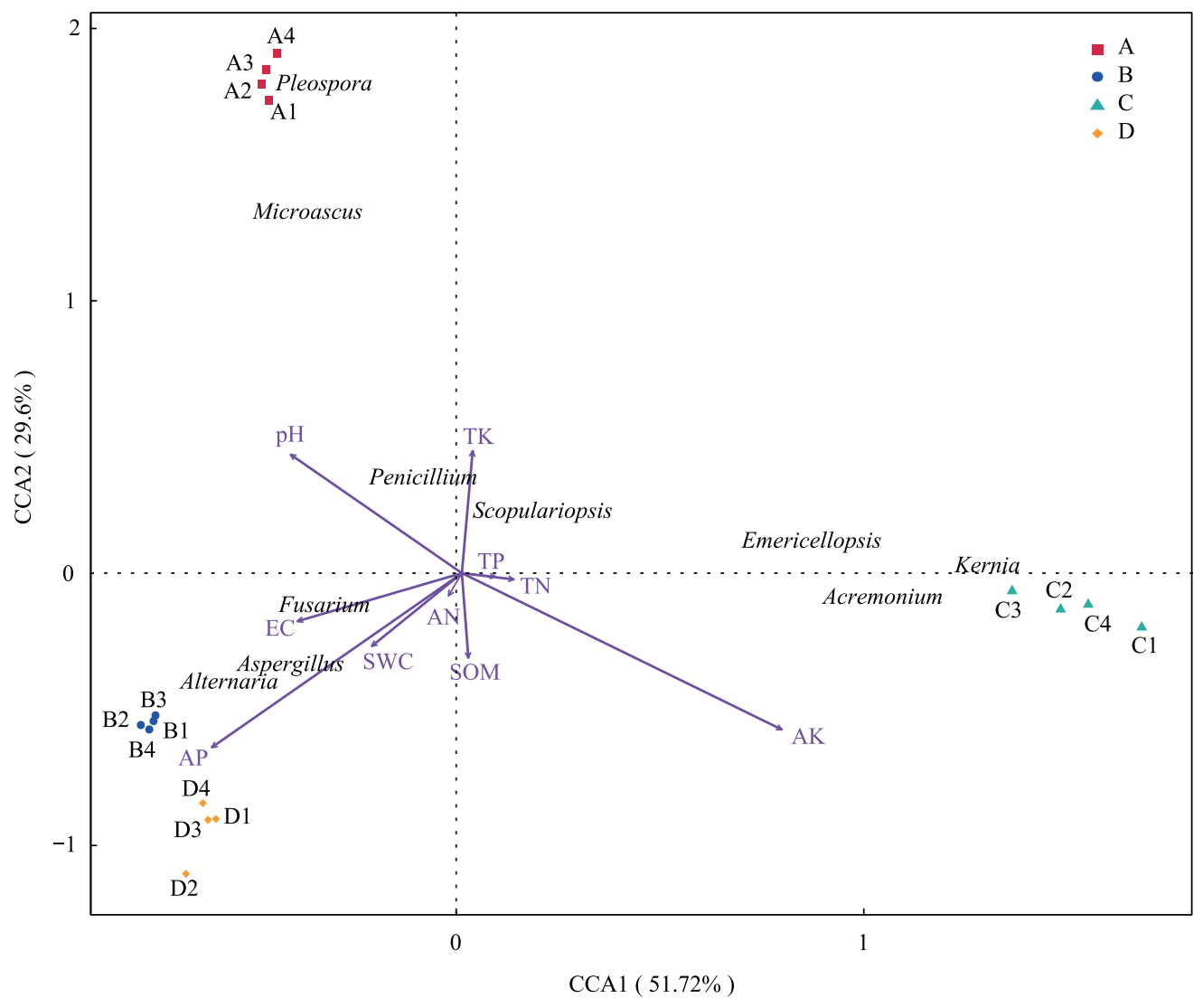

图 7 优势真菌类群与土壤环境因子的 CCA 分析

Fig.7 Canonical correspondence analysis of dominant fungal groups and soil environmental factors

从属水平上物种丰富度与环境因子 Spearman 相关性分析发现 (图 8), 优势菌属中镰孢菌属、曲霉属和链 格孢属与 AP 呈极显著正相关 $(P<0.01)$, 与其它环境因子无显著关系。支顶狍属和帚枝霉属与 AK 呈极显著 正相关 $(P<0.01)$, 与 TK 呈极显著负相关 $(P<0.01)$ 。梨狍帚霉属和翅狍壳属与 AN 、SOM、TN 和 TP 呈极显著 正相关 $(P<0.01)$, 但与 $\mathrm{pH} 、 \mathrm{EC}$ 和 $\mathrm{SWC}$ 呈极显著负相关 $(P<0.01)$ 。微囊菌属、青霉菌属和茎点霉属与 TK 呈 极显著正相关 $(P<0.01)$, 但与 $\mathrm{AK}$ 呈极显著负相关 $(P<0.01)$ 。非优势菌属分布丰度与土壤环境因子之间的 关系各有不同。

\section{3 讨论}

植物对盐碱、旱、寒等逆境的抗性或耐性并不纯粹源于植物基因组本身,根际土壤微生物对宿主适应逆境 
胁迫也有积极影响, 是植物基因组的有效延伸 ${ }^{[16,29-30]}$ 。同时, 宿主植物能够通过根际分泌物成分的复杂变化

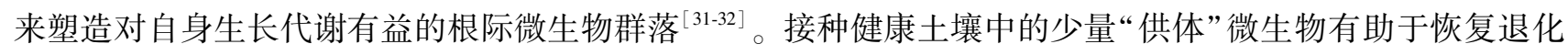
的生态系统,这或许是不同盐碱化土壤深度开发利用的新思路 ${ }^{[33]}$ 。本研究发现南疆四种盐生植物根际土壤 真菌群落组成既具有相似性,也存在一定差异, 表现为优势真菌菌群组成相似,但相对丰度各异, 低丰度菌群 组成也不同。四种植物虽然生长在同一盐碱地中, 但根际土壤理化特性不同, 根际微环境各异, 形成了多样的 真菌群落结构。这反映了根际真菌群落结构的宿主特异性, 印证了不同植物对根际土壤微生物群落结构具有 主动选择性 ${ }^{[34-35]}$ 。即使在同一盐碱生境中, 不同盐生植物也具有不同的根际微环境和真菌群落。

表 3 优势真菌类群与土壤环境因子 envfit 函数检验

Table 3 Envfit permutation function of dominant fungi community and soil environmental factors

\begin{tabular}{lcccc}
\hline 参数 Parameter & CCA1 & CCA2 & $r^{2}$ & $\operatorname{Pr}(>r)$ \\
\hline 土壤酸碱度 $\mathrm{pH}$ & -0.682 & 0.731 & 0.505 & 0.009 \\
电导率 EC & -0.978 & -0.208 & 0.334 & 0.023 \\
土壤含水量 SWC & -0.874 & -0.486 & 0.222 & 0.16 \\
全钾 AN & 0.771 & -0.636 & 0.030 & 0.813 \\
速效磷 AP & -0.665 & -0.747 & 0.725 & 0.001 \\
速效钾 AK & 0.688 & -0.725 & 0.893 & 0 \\
土壤有机质 SOM & 0.427 & -0.904 & 0.154 & 0.325 \\
全氮 TN & 0.975 & -0.222 & 0.097 & 0.495 \\
全磷 TP & 0.979 & -0.205 & 0.073 & 0.608 \\
全钾 TK & 0.479 & -0.878 & 0.237 & 0.167 \\
\hline
\end{tabular}

CCA1 和 CCA2 所对应的值表示环境因子与排序轴的相关性; $r^{2}$ 表示环境因子对物种分布的决定系数, $r^{2}$ 越小,表示该环境因子对物种分布 影响越小
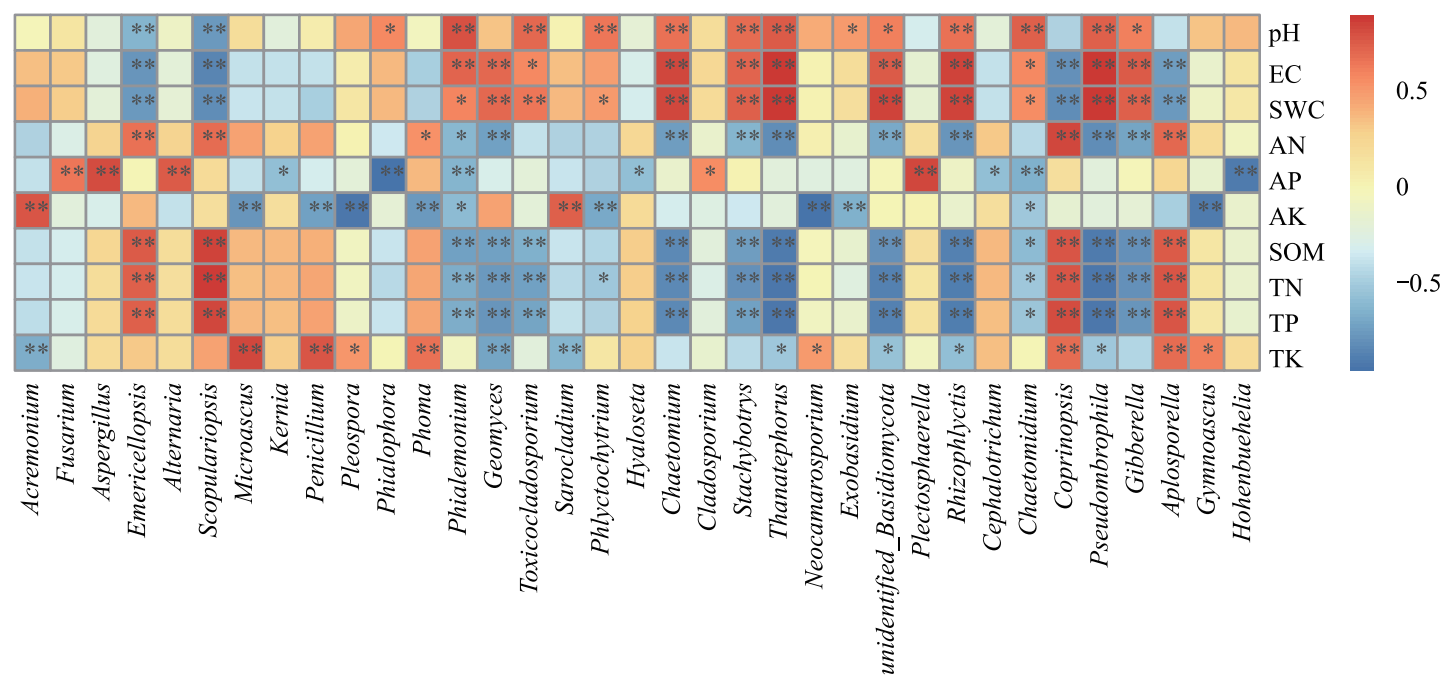

图 8 属水平上物种丰富度与环境因子 Spearman 相关性分析

Fig.8 Spearman correlation analysis of species richness and environmental factor at genus level

“*”表示差异显著 $(P<0.05)$, “* * ”表示差异极显著 $(P<0.01)$

四种盐生植物根际土壤真菌在门水平上的多样性并不丰富, 仅注释到 8 门,且优势门只有 3 门,这可能与 干旱区荒漠盐碱地贫㾑的土壤养分有关。子囊菌门在四种盐生植物根际土壤中占绝对主导地位, 与高寒草 甸、荒漠等生境相似 ${ }^{[22-23,36]}$ 。这与子囊菌门的生活习性有关, 该门是目前真菌中数量最多的类群, 主营腐生 生活, 是土壤中最重要的有机质分解者, 在土壤养分循环方面起着重要作用 ${ }^{[37]}$ 。就植物种类而言, 子囊菌门 
在花花柴根际的相对丰度占比最高 (94.8\%), 而在旱生芦苇根际占比相对较低 $(74.6 \%)$, 这一方面与这两种 植物的根际微环境有关, 花花柴植株冠幅大, 根系粗壮; 而旱生芦苇根系呈匍匐状生长, 须根少且光滑, 进而导 致两种植物根际土壤微环境和真菌群落结构差异。另一方面可能因为子囊菌门作为植物木质素最主要的分 解者,偏好于木质素含量高的环境,旱生芦苇地上冠幅较小,所能形成的茎、叶和根的木质化残屑较少,且难以 堆积在根际; 而盐爪爪、黑果枸杞、花花柴植株相对冠幅大,形成的茎秆、碎叶等木质化残屑容易堆积的根部, 进而被分解进人根际形成了一定的肥岛效应 ${ }^{[38-39]}$ 。壸菌门主要分布在盐爪爪和旱生芦苇根际, 在黑果枸杞 和花花柴根际几乎没有分布, 推测也与该门的生活习性有关。壶菌门是真菌界中唯一在生活史中可产生游动 孢子的成员,多为水生,大多腐生在动植物残体上或寄生于水生植物上。旱生芦苇虽属旱芦,但根系十分发 达, 喜水且能借助根系吸取更多水分, 近而营造出适宜该门真菌生长繁殖的根际微生境。

从属水平上看, 镰狍菌属、支顶狍属和曲霉属是四种盐生植物根际土壤的共同优势菌属, 但相对丰度上具 有植物特异性。镰狍菌属在花花柴根际的相对丰度显著低于其它三种植物, 但花花柴根际的支顶狍属和翅饱 壳属丰度却显著高于其它植物, 且以支顶孢属占绝对主导地位。菌群相对丰度表现出植物特异性, 这可能与 不同宿主植物的生长特性和根际微环境有关。植物通过茎、叶、根的调落物以及根系分泌物向地下输送 $\mathrm{C}$ 物 质, 供根际微生物菌群分解利用, 同时根际土壤微生物又通过感染根部形成共生关系 (如菌根), 或通过产生 植物激素促进植物生长, 或减少植物胁迫信号, 从而与植物互作 ${ }^{[40]}$ 。有研究显示, 镰狍菌属通过产生木质纤 维素酶对 $\mathrm{C}$ 的分解起作用,并与曲霉属共同参与土壤中难溶性磷的溶解, 在促进植物对磷的吸收方面意义重 $大^{[41]}$, 曲霉属被大量报道属于嗜盐真菌, 普遍分布于各类高盐环境中 ${ }^{[42]}$ 。支顶孢属被认为是一类生防菌, 对 多种致病真菌有抑制作用, 它作为花花柴根际土壤中的绝对优势真菌很可能与其根际病原真菌帚枝䨢属丰度 的大幅增加有关,而该属病原菌在其它植物根际的丰度极低。

不同植物的遗传背景和物质代谢过程造就了不同的根际微环境, 影响微生物群落结构。从真菌群落与土 壤理化因子的相关性看, 土壤速效钾、速效磷、 $\mathrm{pH}$ 和电导率是影响四种盐生植物真菌群落分布的主要驱动因 子。盐爪爪与早生芦苇根际土壤 $\mathrm{pH}$ 和 $\mathrm{EC}$ 值较高, 真菌群落丰富度和多样性指数也相对较高, 推测土壤 $\mathrm{pH}$ 和 EC 可能是决定盐碱生境中植物根际真菌群落丰富度的关键因子。从四种盐生植物根际土壤真菌群落聚 类分析结果看,盐爪爪和旱生芦苇共有的 OTUs 数量最多,而且壹菌门是它们的次优势菌门,但该门真菌在另 外两种植物根际没有发现, 表明土壤 $\mathrm{pH}$ 和 EC 不仅会影响盐生植物根际真菌群落丰富度, 还会影响其多样 性。镰孢菌属、曲霉属和链格狍属中很多具有解磷功能, 能够分解土壤中的难溶性磷供植物吸收 ${ }^{[41-42]}$, 它们 作为黑果枸杞根际的主要优势菌属, 与其根际土壤 AP 含量最高有直接对应关系。说明这些真菌有效溶解了 黑果枸杞根际土壤中的难溶性磷, 转化为可溶态, 增加了其对磷的吸收利用。

ITS(Internal Transcribed Spacer) 扩增子测序技术,具有传统真菌分类方法不可比拟的优势, 已成为当前研 究真菌群落多样性的首选之策。但就扩增子测序而言,对其结果准确性影响最大的因素是样品采集和基因组 提取工作。本研究采取多点混合采样法得到每种植物 4 个重复样品, 在一定程度上代表了样本的真实情况, 但无法绝对准确代表样本。增加样品数量可以在一定意义上解决这一问题, 但随之测序成本也会显著提高, 因此需要在最经济的成本下确定样品数量。根际是植物根系-土壤界面数毫米区域内受植物根系影响最大, 呈现独特的土壤理化和生物学特性且处于动态变化的土壤微域。目前运用较多的根际土壤获取方法一是抖 落与根系结合松散的土壤后用无菌毛刷刷取紧贴根系的土壤; 二是用缓冲液混合玻璃珠振荡以取得根际样 品。两种方法各有利弊,须结合实际选用并不断改进。

\section{参考文献 (References) :}

[ 1 ] Ma J B, Zhang M R, Xiao X L, You J J, Wang J R, Wang T, Yao Y N, Tian C Y. Global transcriptome profiling of Salicornia europaea L. shoots under NaCl treatment. PLoS One, 2013, 8(6) : e65877.

[ 2 ] Bouchhima R A, Sarti M, Ciolfi M, Lauteri M, Ksibi M. Decision tree for mapping of halophyte cover around Ghannouch, Tunisia. Environmental Monitoring and Assessment, 2018, 190(12) : 742. 
[ 3 ] Mora-Ruiz M D R, Alejandre-Colomo C, Ledger T, González B, Orfila A, Rosselló-Móra R. Non-halophilic endophytes associated with the euhalophyte Arthrocnemum macrostachyum and their plant growth promoting activity potential. FEMS Microbiology Letters, 2018, 365 (19) : fny208.

[ 4 ] Sonali S, Venkata M, Luis S, Renesh B, Rohit J, Kanniah R, Niranjan B. An actin-depolymerizing factor from the halophyte smooth cordgrass, Spartina alterniflora ( $S a A D F 2)$, is Superior to its Rice homolog ( $S A A D F 2$ ) in conferring drought and salt tolerance when constitutively overexpressed in rice. Plant Biotechnology Journal, 2019, 17(1) : 188-205.

[ 5 ] Van Zelm E V, Zhang Y X, Testerink C. Salt tolerance mechanisms of plants. Annual Review of Plant Biology, 2020, 71( 1) : 403-433.

[6] 张爱琴, 庞秋颖, 阎秀峰. 碱蓬属植物耐盐机理研究进展. 生态学报, 2013, 33(12): 3575-3583.

[ 7 ] Bencherif K, Boutekrabt A, Fontaine J, Laruelle F, Dalpè Y, Sahraoui A L H. Impact of soil salinity on arbuscular mycorrhizal fungi biodiversity and microflora biomass associated with Tamarix articulata Vahll rhizosphere in arid and semi-arid Algerian areas. Science of the Total Environment, $2015,533: 488-494$.

[ 8 ] Chandrasekaran M, Boughattas S, Hu S J, Oh S H, Sa T M. A meta-analysis of arbuscular mycorrhizal effects on plants grown under salt stress. Mycorrhiza, 2014, 24(8): 611-625.

[ 9 ] Baum C, El-Tohamy W, Gruda N. Increasing the productivity and product quality of vegetable crops using arbuscular mycorrhizal fungi : a review. Scientia Horticulturae, 2015, 187: 131-141.

[10] Tisarum R, Theerawitaya C, Samphumphuang T, Polispitak K, Thongpoem P, Singh H P, Cha-Um S. Alleviation of salt stress in upland rice (Oryza sativa L. ssp. indica cv. Leum Pua) using arbuscular mycorrhizal fungi inoculation. Frontiers in Plant Science, 2020 , 11 : 348.

[11] Lee Y, Krishnamoorthy R, Selvakumar G, Kim K, Sa T. Alleviation of salt stress in maize plant by co-inoculation of arbuscular mycorrhizal fungi and Methylobacterium oryzae CBMB20. Journal of the Korean Society for Applied Biological Chemistry, 2015, 58(4) : 533-540.

[12] Etesami H. Can interaction between silicon and plant growth promoting rhizobacteria benefit in alleviating abiotic and biotic stresses in crop plants? Agriculture, Ecosystems \& Environment, 2018, 253: 98-112.

[13] Etesami H, Beattie G A. Mining halophytes for plant growth-promoting halotolerant bacteria to enhance the salinity tolerance of non-halophytic crops. Frontiers in Microbiology, 2018, 9: 148.

[14] Sarkar J, Chakraborty B, Chakraborty U. Plant growth promoting rhizobacteria protect wheat plants against temperature stress through antioxidant signalling and reducing chloroplast and membrane injury. Journal of Plant Growth Regulation, 2018, 37(4) : 1396-1412.

[15] Tiepo A N, Hertel M F, Rocha S S, Calzavara A K, De Oliveira A L M, Pimenta J A, Oliveira H C, Bianchini E, Stolf-Moreira R. Enhanced drought tolerance in seedlings of Neotropical tree species inoculated with plant growth-promoting bacteria. Plant Physiology and Biochemistry, 2018, 130: 277-288.

[16] Keswani C, Prakash O, Bharti N, Vílchez J I, Sansinenea E, Lally R D, Borriss R, Singh S P, Gupta V K, Fraceto L F, De Lima R, Singh H B. Re-addressing the biosafety issues of plant growth promoting rhizobacteria. Science of the Total Environment, 2019, 690: 841-852.

[17] Fierer N. Embracing the unknown: disentangling the complexities of the soil microbiome. Nature Reviews Microbiology, 2017, 15(10): 579-590.

[18] Mahoney A K, Yin C T, Hulbert S H. Community structure, species variation, and potential functions of rhizosphere-associated bacteria of different winter wheat (Triticum aestivum) cultivars. Frontiers in Plant Science, 2017, 8: 132

[19] Raaijmakers J M, Mazzola M. Soil immune responses. Science, 2016, 352(6292) : 1392-1393.

[20] Numan M, Bashir S, Khan Y, Mumtaz R, Shinwari Z K, Khan A L, Khan A, AL-Harrasi A. Plant growth promoting bacteria as an alternative strategy for salt tolerance in plants: a review. Microbiological Research, 2018, 209: 21-32.

[21] Palacio-Rodríguez R, Coria-Arellano J L, López-Bucio J, Sánchez-Salas J, Muro-Pérez G, Castañeda-Gaytán G, Sáenz-Mata J. Halophilic rhizobacteria from Distichlis spicata promote growth and improve salt tolerance in heterologous plant hosts. Symbiosis, 2017, 73(3): 179-189.

[22] 赵兴鸽, 张世挺, 牛克昌. 青藏高原高寒草甸土壤真菌多样性与植物群落功能性状和土壤理化特性的关系. 应用与环境生物学报, 2020, $26(1): 1-9$.

[23] 王健铭, 中国温带荒漠区植物与土壤微生物多样性地理格局及其环境解释, 2019, 北京林业大学.

[24] 田长彦, 买文选, 赵振勇. 新疆干旱区盐碱地生态治理关键技术研究. 生态学报, 2016, 36(22): 7064-7068.

[25] 李和平, 田长彦, 乔木, 吴世新. 新疆耕地盐渍土遥感信息解译标志及指标探讨. 干旱地区农业研究, 2009, 27(2): 218-222.

[26] 鲍士旦. 土壤农化分析(第三版). 北京: 中国农业出版社, 2000.

[27] Miao L, Wang S Y, Li B K, Cao T H, Zhang F Z, Wang Z, Peng Y Z. Effect of carbon source type on intracellular stored polymers during endogenous denitritation (ED) treating landfill leachate. Water Research, 2016, 100: 405-412.

[28] Bokulich N A, Subramanian S, Faith J J, Gevers D, Gordon J I, Knight R, Mills D A, Caporaso J G. Quality-filtering vastly improves diversity estimates from Illumina amplicon sequencing. Nature Methods, 2013, 10(1): 57-59.

[29] Kearl J, McNary C, Lowman J S, Mei C S, Aanderud Z T, Smith S T, West J, Colton E, Hamson M, Nielsen B L. Salt-tolerant halophyte 
rhizosphere bacteria stimulate growth of alfalfa in salty soil. Frontiers in Microbiology, 2019, 10: 1849.

[30] Hashem A, Tabassum B, Abd_Allah E F. Bacillus subtilis : a plant-growth promoting rhizobacterium that also impacts biotic stress. Saudi Journal of Biological Sciences, 2019, 26(6): 1291-1297.

[31] Tkacz A, Cheema J, Chandra G, Grant A, Poole P S. Stability and succession of the rhizosphere microbiota depends upon plant type and soil composition. The ISME Journal, 2015, 9(11): 2349-2359.

[32] Pii Y, Borruso L, Brusetti L, Crecchio C, Cesco S, Mimmo T. The interaction between iron nutrition, plant species and soil type shapes the rhizosphere microbiome. Plant Physiology and Biochemistry, 2016, 99: 39-48.

[33] Wubs E R J, Van Der Putten W H, Bosch M, Bezemer T M. Soil inoculation steers restoration of terrestrial ecosystems. Nature Plants, 2016, 2 (8) : 16107 .

[34] De Vries F T, Griffiths R I, Knight C G, Nicolitch O, Williams A. Harnessing rhizosphere microbiomes for drought-resilient crop production. Science, 2020, 368(6488): 270-274.

[35] Floc'h J B, Hamel C, Harker K N, St-Arnaud M. Fungal communities of the canola rhizosphere: keystone species and substantial between-year variation of the rhizosphere microbiome. Microbial Ecology, 2020, 80(4) : 762-777.

[36] 李海云, 姚拓, 高亚敏, 张建贵, 马亚春, 路晓雯, 杨晓蕾, 张慧荣, 夏东慧. 退化高寒草地土壤真菌群落与土壤环境因子间相互关系. 微生物学报, 2019, 59(4): 678-688.

[37] 杨盼, 翟亚萍, 赵祥, 王绍明, 刘红玲, 张霞. AM 真菌和根瘤菌互作对苜宿根际土壤真菌群落结构的影响及功能预测. 草业科学, 2020, $37(9): 1669-1680$.

[38 ] De Araujo A S F, Bezerra W M, Dos Santos V M, Nunes L A P L, De Lyra M D C C P, Figueiredo M D V B, Melo V M M. Fungal diversity in soils across a gradient of preserved Brazilian Cerrado. Journal of Microbiology, 2017, 55(4) : 273-279.

[39] Van Der Wal A, Van Veen J A, Smant W, Boschker H T S, Bloem J, Kardol P, Van Der Putten W H, De Boer W. Fungal biomass development in a chronosequence of land abandonment. Soil Biology and Biochemistry, 2006, 38(1): 51-60.

[40] Bulgarelli D, Schlaeppi K, Spaepen S, Van Themaat E V L, Schulze-Lefert P. Structure and functions of the bacterial microbiota of plants. Annual Review of Plant Biology, 2013, 64: 807-838.

[41] 杨顺, 杨婷, 林斌, 刘杏忠, 向梅春. 两株溶磷真菌的篮选、鉴定及溶磷效果的评价. 微生物学报, 2018, 58(2): 264-273.

[42] Musa H, Kasim F H, Gunny A A N, Gopinath S C B. Salt-adapted moulds and yeasts : potentials in industrial and environmental biotechnology. Process Biochemistry, 2018, 69: 33-44. 